\title{
Restless legs syndrome and nocturnal myoclonus: initial clinical manifestation of familial amyloid polyneuropathy
}

\author{
F Salvi, P Montagna, R Plasmati, G Rubboli, F Cirignotta, M Veilleux, E Lugaresi, \\ C A Tassinari
}

\begin{abstract}
Restless legs syndrome was the first isolated clinical manifestation in four siblings of a family with familial amyloid polyneuropathy. Clinical and electrophysiological evidence of peripheral neuropathy appeared after a variable time interval. Polysomnography showed abnormal sleep patterns and nocturnal myoclonus in all patients. The restless legs syndrome responded favourably to clonazepam.
\end{abstract}

The restless legs syndrome (RLS) is characterised by deep, ill-defined paraesthesiae associated with restlessness of the lower limbs, appearing when the patient falls asleep or during prolonged rest. ${ }^{1-3}$ Movements or rubbing of the legs usually relieve the symptoms. RLS has been reported as an idiopathic, often familial condition, ${ }^{24-6}$ or associated with polyneuropathies. ${ }^{2}$ On polysomnography, RLS is frequently accompanied by periodic movements of sleep, also called nocturnal myoclonus (NM). ${ }^{237}$

In 1952 Andrade first described a family with an atypical generalised amyloidosis predominantly involving the peripheral nerves. ${ }^{8}$ An Italian family with familial amyloid polyneuropathy (FAP) bearing the biochemical marker of the Portuguese variant (transthyretin-Met 30, TTR-Met30) was recently studied. ${ }^{9}{ }^{10}$ Four of the five clinically affected family members complained of RLS months to years before the onset of clinical symptoms of polyneuropathy. To our knowledge RLS and NM have not been reported in patients with FAP.

\section{Material and methods}

Thirty three living members of the family over three generations were examined and followed over a period of more than three years. All were tested for TTR-Met30. Eleven of them were found to be carriers of the TTRMet30 marker; of these, only three had clinical evidence of polyneuropathy at the time of the TTR-Met30 typing (cases II-1, 10, 12, fig 1). At follow up, two additional family mem- bers (cases II-2 and 6, fig 1) were shown to have FAP. A skin biopsy showing amyloid deposits confirmed the diagnosis of FAP in all patients and, in one of them, a sural nerve biopsy revealed similar findings.

Four of the five clinically affected patients complained of RLS and their case histories are summarised below. Standard motor and sensory nerve conduction studies (NCS) and concentric needle electrode examination (NEE) of the lower extremities were performed in all four patients according to the Buchthal's method. " Sympathetic skin responses (SSR) were recorded from the palm using a technique previously described. ${ }^{12}$ These patients had a polysomnographic study which included recording the electroencephalogram (EEG), electro-oculogram (EOG), electromyogram (EMG) of the submental muscles, electrocardiogram (ECG), respirogram, and EMG of the anterior tibialis muscle. ${ }^{713}$ The presence of NM was determined according to previously reported indices. $^{7}$

\section{Case reports}

Case 1 Case II-1 is a 71 year old housewife. Since the age of 61 years she had complained of an ill-defined sensation of pulling and tearing in the distal lower extremities while falling asleep, usually relieved by movements although, on occasion, she had to get up and walk for a few minutes. She would sleep for only a few hours because of the difficulty in falling asleep and the frequent awakenings. Neurological examination at that time was normal. At the age of 65 years, she noticed the onset of diurnal burning pain and swarming paraesthesiae on the anterolateral aspect of the legs distal to the knee. Two years later this continuous burning sensation also involved her feet and hands. Four years later electrophysiological studies including NCS and concentric NEE were consistent with a severe sensorimotor peripheral neuropathy (table). SSR were absent. A polysomnography confirmed the presence of NM. She was treated with clonazepam $1 \mathrm{mg}$ Hs which considerably relieved the RLS; however, the medication was discontinued one year later because of 
Figure 1 Family pedigree.

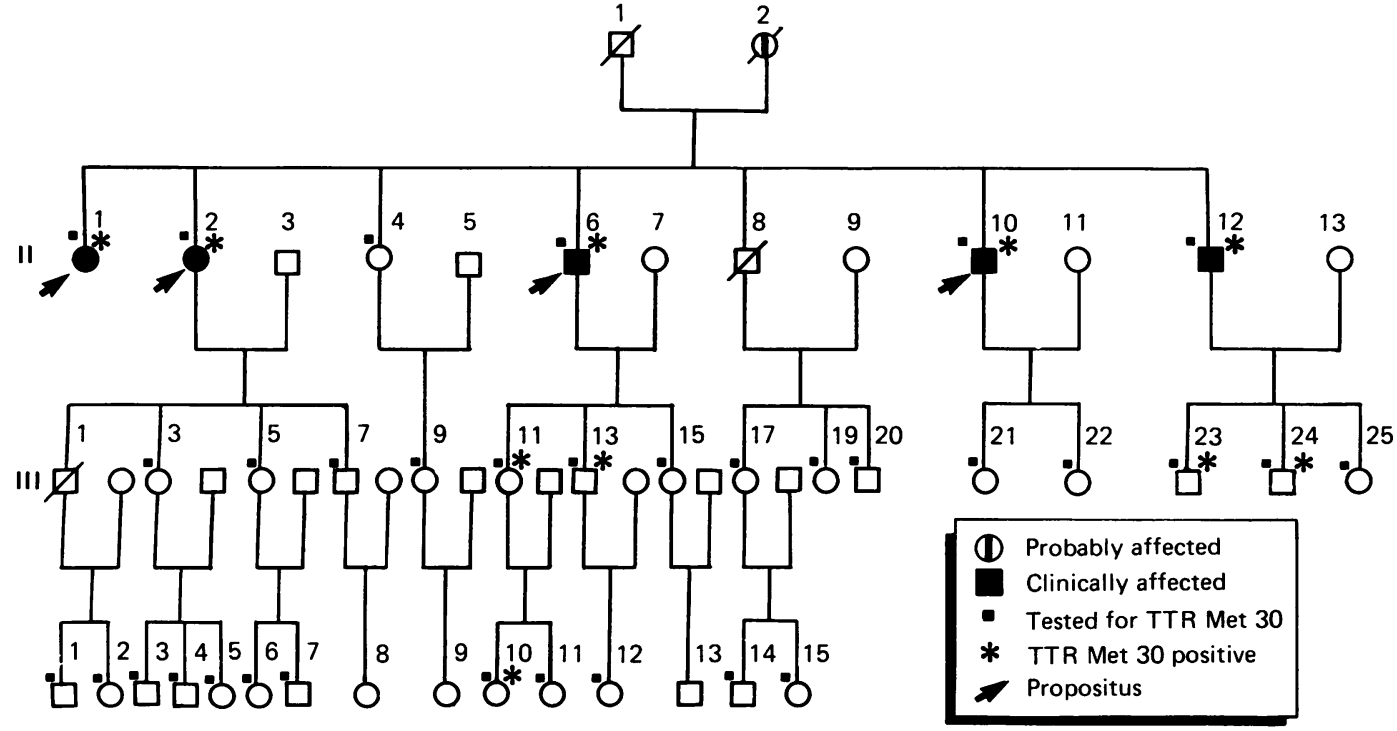

increased muscle weakness and the symptoms of RLS recurred. At the age of 71 years she became bedridden and, on neurological examination, she had marked predominantly distal muscle atrophy, distal limb anaesthesia, faecal and urinary incontinence, and episodes of orthostatic hypotension.

Case 2 Case II-10 is a 54 year old fisherman who reported a three year history of paraesthesiae described as electric shocks or pinpricks felt as a deep sensation in the distal lower limbs while trying to fall asleep. He had to rub or move his legs and sometimes walk to get some relief. These paraesthesiae would result in several awakenings during the night. According to his wife, the patient had sudden jerks of the lower extremities while asleep. All these symptoms would also occur during daytime although only when resting. At the age of 52 years, he began complaining of diurnal superficial paraesthesiae and loss of pain and temperature sensation in the lower extremities, and burning pain in the soles of his feet. A year later, he reported a difficulty in maintaining an erection and a few episodes of faecal and urinary incontinence. Clinical examination and electrophysiological studies confirmed the presence of a mixed sensorimotor peripheral neuropathy (table). SSR were present but of low amplitude. A polysomnographic study was obtained at the age of 54 years. He was treated with clonazepam $1 \mathrm{mg} \mathrm{Hs}$ which relieved the symptoms associated with RLS. The latter recurred each time he withdrew from the treatment.

Case 3 Case II-2 is a 69 year old housewife who had been complaining of a sensation of "tightening" deep in the legs and ankles. She described it as "something biting my bones", and this caused her some difficulty in falling asleep. Movements or rubbing of the legs gave her a temporary relief. At the age of 66 years, a neurological examination and electrophysiological studies including NCS, NEE and SSR were completely normal. Treatment with clonazepam $1 \mathrm{mg} \mathrm{Hs}$, started shortly following a polysomnograph, completely relieved her symptoms (to date medication is still effective). At age 68 years (30 months after the onset of RLS), she noticed the onset of diurnal pain, paraesthesiae and loss of sensation on the lateral part of the legs. Neurological examination revealed definite signs of a peripheral neuropathy and NCS showed slightly reduced nerve conduction velocities (table). SSR were present but of low amplitude.

Case 4 Case II-6 is a 63 year old fisherman with a past medical history of diabetes mellitus, diagnosed at the age of 55, and wellcontrolled by an oral hypoglycaemic agent. When first seen at the age of 60 , he was asymptomatic and his neurological examination and electrophysiological studies including SSR were normal. One year later he began to complain of deep paraesthesiae in his legs and feet with a feeling of constriction and warmth appearing about 30 minutes after falling asleep. To obtain relief, he needed to move or rub his legs continuously. A repeat electrophysiological testing was normal. A diagnosis of RLS was made on a clinical basis. Following a polysomnogram, he was treated with clonazepam $1 \mathrm{mg} \mathrm{Hs}$ which dramatically relieved the symptoms. The latter recurred each time the patient attempted to stop the medication because of daytime somnolence. Nine months later he began complaining of diurnal superficial dysaesthesiae localised to the anterolateral aspect of his legs. Clinical examination and NCS performed at that time revealed a mild mixed peripheral neuropathy in the lower extremities (table).

\section{Results}

All patients showed abnormal sleep patterns with reduction of the deep sleep stages (stages III and IV). In all but one (case 4), REM sleep was reduced. Sleep latency was not increased. Numerous arousals appeared during sleep and in cases 3 and 4, the wake after sleep onset (WASO) index was highly increased. During relaxed wakefulness and nocturnal awakenings, abundant EMG activity was recorded from the anterior tibialis muscle showing nearly contin- 
Table Results of motor and sensory NCS and SSR (expressed in \% of normal values)

\begin{tabular}{|c|c|c|c|c|c|c|c|c|c|c|c|}
\hline \multirow{2}{*}{$\begin{array}{l}\text { Case } \\
\text { Age }\end{array}$} & \multicolumn{4}{|l|}{1} & \multicolumn{3}{|l|}{2} & \multicolumn{2}{|l|}{3} & \multicolumn{2}{|l|}{4} \\
\hline & 69 & 70 & 70 & 71 & 53 & 53 & 55 & 66 & 68 & 60 & 62 \\
\hline \multicolumn{12}{|l|}{$\begin{array}{l}\text { Median } \\
\text { Motor }\end{array}$} \\
\hline $\begin{array}{l}\text { MAP } \\
\text { MCV }\end{array}$ & & $\begin{array}{l}N \\
63\end{array}$ & & & & $\begin{array}{l}N \\
81\end{array}$ & & & & & \\
\hline Sensory & & & & & & & & & & & \\
\hline $\begin{array}{l}\text { SAP } \\
\text { SCV }\end{array}$ & & $\begin{array}{r}6 \\
17\end{array}$ & & & & N1 & & & & & \\
\hline \multirow{2}{*}{\multicolumn{12}{|c|}{ Ulnar }} \\
\hline & & & & $\mathrm{N}$ & & & & & & & \\
\hline $\begin{array}{r}\text { MCV } \\
\text { Sensory }\end{array}$ & & & & $\mathbf{N}$ & & & & & & & \\
\hline $\begin{array}{c}\text { Sensory } \\
\text { SAP }\end{array}$ & & & & & & & & & & & \\
\hline SCV & & & & $\mathbf{N}$ & & & & & & & \\
\hline \multicolumn{12}{|l|}{$\begin{array}{l}\text { Peroneal } \\
\text { Motor }\end{array}$} \\
\hline $\begin{array}{c}\text { Motor } \\
\text { MAAP }\end{array}$ & & 0 & 0 & & $\mathbf{N}$ & & & $\mathbf{N}$ & $\mathbf{N}$ & $\mathbf{N}$ & $\mathbf{N}$ \\
\hline $\mathrm{MCV}$ & $\mathbf{N}$ & 0 & 0 & & 82 & & & $\mathbf{N}$ & $\mathbf{N}$ & $\mathbf{N}$ & 78 \\
\hline $\begin{array}{c}\text { Sensory } \\
\text { SAP }\end{array}$ & 0 & 11 & & & $\mathbf{N}$ & & & $\mathbf{N}$ & $\mathbf{N}$ & $\mathbf{N}$ & $\mathbf{N}$ \\
\hline SCV & 0 & 70 & & & $\mathbf{N}$ & & & $\mathbf{N}$ & $\mathbf{N}$ & $\mathbf{N}$ & $\mathbf{N}$ \\
\hline \multicolumn{12}{|l|}{ Sural } \\
\hline $\begin{array}{l}\text { SAP } \\
\text { SCV }\end{array}$ & & 1 & 0 & & $\begin{array}{l}\mathrm{N} \\
83\end{array}$ & & $\begin{array}{r}1 \\
60\end{array}$ & $\stackrel{\mathbf{N}}{\mathbf{N}}$ & $\begin{array}{l}\mathbf{N} \\
87\end{array}$ & $\mathbf{N}$ & $\stackrel{N}{N}$ \\
\hline SSR & & & & 0 & 1 & & 0 & $N$ & 1 & $\mathbf{N}$ & $\mathbf{N}$ \\
\hline
\end{tabular}

0: absence of motor or sensory action potential; N: normal; $\downarrow$ : reduced amplitude; MAP: motor action potential amplitude; MCV: motor conduction velocity; SAP: sensory action potential amplitude; SCV: sensory conduction velocity; SSR: sympathetic skin response.

uous leg movements. All patients had periodic movements typical of NM (fig 2). In cases 1,2 , and 4 , the myoclonus index (number of movements per hour of sleep) was $28 \cdot 5,15$, and 11.4 respectively which is above the upper limit of normal. ${ }^{7}$

\section{Discussion}

In our patients the symptoms of RLS were clearly different from the hyperpathia and formication usually found in polyneuropathy. Not only were they present exclusively during muscular rest and relieved by movements, but they were localised deeply in the legs and accompanied by a constricting or biting sensa- tion and an urge to move the limbs. Patients could clearly differentiate between the RLS and the superficial paraesthesiae which developed later.

To our knowledge, an association between RLS-NM and FAP has not been previously reported although a case of RLS associated with sporadic amyloid neuropathy has been described. ${ }^{14}$

Evidence suggests a close, not casual, pathogenetic relationship between FAP and RLS-NM. First, no member of the present family without FAP complained of RLS. There was a definite time sequence between the symptom-free period, RLS-NM and polyneuropathy. RLS was the first symptom to
Figure 2

Polysomnographic in case 4. Periodic movements of sleep recorded from the anterior tibialis muscles, intermingled with brief, irregular myoclonic bursts.

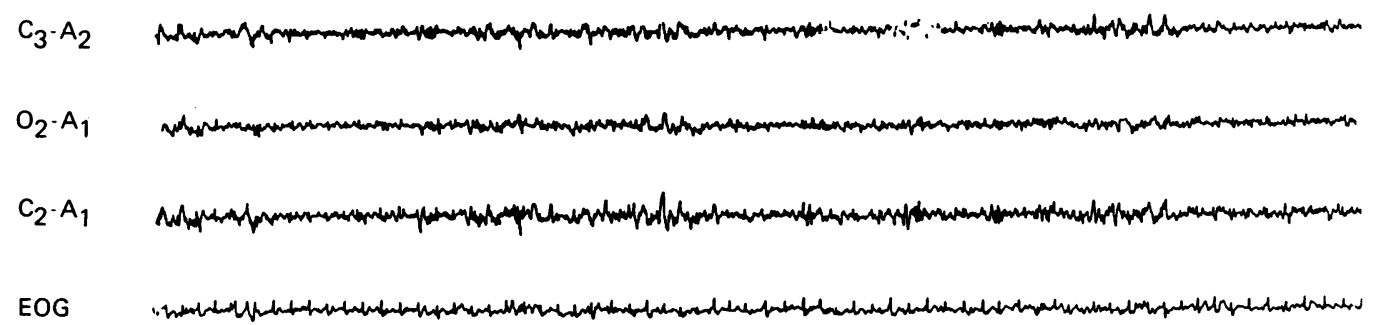

MyloEMG

ECG

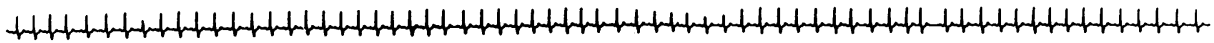

R. tib. ant.

L. tib. ant.

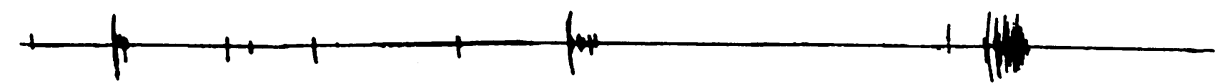

Thor. resp.

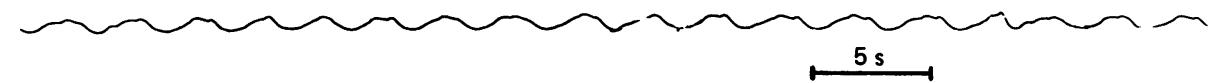


appear even when neurological examination and electrophysiological studies proved negative for polyneuropathy. Second, the follow up of two asymptomatic marker-positive patients (cases 3 and 4 ) allowed us to detect the onset of RLS nine and 30 months before they developed the symptoms and signs of a sensorimotor and autonomic polyneuropathy typical of FAP. RLS-NM and FAP presented in a chronological order and RLS persisted even in the presence of a full-blown FAP. Finally, RLS in our patients had a mean age at onset of 59.7 years while in the previously reported familial cases, the onset was usually during adolescence. ${ }^{4-6}$

In our opinion, RLS was an early symptom of FAP and should be thoroughly looked for in patients with FAP. RLS with FAP cannot be clinically differentiated from the idiopathic variant except for its later age of onset. Both are promptly amenable to medical management. ${ }^{15-17}$ In our patients, clonazepam $1 \mathrm{mg}$ in a single bedtime dose led to a marked benefit with complete relief of RLS symptoms. Clonazepam had to be withdrawn in two patients because of daytime drowsiness and muscle weakness. However, the two patients still under treatment continue to benefit from the medication in spite of the evolution of the disease.

The origin and physiopathology of RLS and NM are still largely hypothetical. ${ }^{6}$ However, in some cases, RLS-NM may be associated with an early peripheral nervous system involvement such as seen in our patients with FAP. In view of this, patients with apparently idiopathic, late onset RLS should be thoroughly investigated to discover a possible underlying cause, particularly if there is a family history.

Since the completion of our study, all five members of two additional families with late onset FAP were found to have RLS early in the course of the disease followed by clinical, pathological, and electrophysiological evidence of polyneuropathy. All patients also had a marked improvement in the symptoms of RLS on clonazepam.
We thank Drs P P Costa and M J M Saraiva from the University of Porto, Portugal, for TTR-Met30 typing.

1 Ekbom K. Restless legs: a clinical study. Acta Med Scand $1945 ; 158: 1-123$.

2 Ekbom K. Restless legs. In: Vinken PJ, Bruyn GW, Klawan HL, eds. Handbook of Clinical Neurology, Vol. 51 Neuropathies. Amsterdam: Elsevier Science Publishers, 1987:543-50.

3 Lugaresi E, Cirignotta F, Coccagna G, Montagna P Nocturnal myoclonus and restless legs syndrome. In Fahn et al, eds. Advances in Neurology, Vol 43: Myoclonus. New York: Raven Press, 1986:295-307.

4 Montagna P, Coccagna G, Cirignotta F, Lugaresi E. Familial restless legs syndrome: long term follow-up. In: Guilleminault $C$, Lugaresi $E$, eds. Sleep-wake disorder: natural history, epidemiology and long-term evolution. New York: Raven Press, 1983:231-5.

5 Boghen D, Peyronnard JM. Myoclonus in familial restless legs syndrome. Arch Neurol 1976;33:368-70.

6 Montplaisir J, Godbout R, Boghen D, de Champlain J, Young SN, Lapierre G. Familial restless legs with periodic movements in sleep: electrophysiologic, biochemical, and pharmacologic study. Neurology 1985;35 $130-4$.

7 Coleman RM. Periodic movements in sleep (nocturnal myoclonus) and restless legs syndrome. In: Guilleminault $\mathrm{C}$, ed. Sleeping and waking disorders: indications and techniques. Palo Alto, California: Addison-Wesley, 1982 265-95.

8 Andrade C. A peculiar form of peripheral neuropathy: Familial atypical generalized amyloidosis with special involvement of the peripheral nerves. Brain 1952;75: 408-27.

9 Saraiva MJM, Birkin S, Costa PP, Goodman DS. Amyloid fibril protein in familial amyloidotic polyneuropathy, Portuguese type: definition of molecular abnormality in transthyretin (prealbumin). J Clin Invest 1984:74:104-19.

10 Ferlini A, Romeo G, Tassinari CA, Saraiva MJM, Costa PP Salvi F. Discrimination of peripheral neuropathies caused by TTR variant or diabetes in the same pedigree through protein studies. In: Di Donato S, Mamoli A, Di Mauro S Rowland LP, eds. Advances in Neurology, Vol. 48 Molecular genetics and neuromuscular disease. New York Raven Press, 1988:201-8.

11 Rosenfalk P, Rosenfalk A. Electromyography: sensory and motor conduction findings in normal subjects. Rigshospitalet. Copenhagen 1975:1-4.

12 Shahani BT, Halperin JJ, Boulu P, Cohen J. Sympathetic skin response: a method of assessing unmyelinated axon skin response: a method of assessing unmyelinated axon
dysfunction in peripheral neuropathies. $J$ Neurol dysfunction in peripheral neuropath
Neurosurg Psychiatry 1984;47:536-42.

13 Rechtschaffen A, Kales A. A manual of standardized terminology, techniques and scoring system for sleep stages of ology, techniques and scoring system for sleep stages of
human subjects. Brain Information Service. Brain human subjects. Brain Information Service.
Research Institute: UCLA, Los Angeles, 1968.

14 Heinze EG, Frame B, Fine G. Restless legs and orthostatic hypotension in primary amyloidosis. Arch Neurol 1967; 16:497-500

15 Oshtory MA, Vijayan N. Clonazepam treatment of insomnia due to sleep myoclonus. Arch Neurol 1980;37:119-20.

16 Montagna P, Sassoli de Bianchi L, Zucconi M, Cirignotta F, Lugaresi $\mathrm{E}$. Clonazepam and vibration in restless legs syndrome. Acta Neurol Scand 1984;69:428-30.

17 Boghen D, Lamothe L, Elie R, Godbout R, Montplaisir J. The treatment of the restless legs syndrome with clonazepam: a prospective controlled study. Can J Neurol Sci $1986 ; 13: 245-7$. 